\title{
Synthesis and Characterization of New Polymer Systems Containing Indole
}

\author{
Mohamad Hosein Nasirtabrizi*, Hamideh Saberi Khosroshahi
}

\section{ART ICLE INF O}

Received: 28 December 2018

Revised: 2 January 2019

Accepted: 25 February 2019

Available online: 26 March 2019

DOI: 10.33945/SAMI/AJCA.2019.2.256265

\section{K E Y W O R D S}

Chemical modification

Maleic anhydride

Indole

Dynamic mechanical thermal analysis (DMTA)

Glass transition temperature

\begin{abstract}
A B S T R A C T
Synthesis of some novel indole derivatives has been undertaken by the reaction of poly(maleic anhydride- $c o$-styrene), $\mathrm{P}(\mathrm{MA}-\mathrm{co}-\mathrm{St})$, poly(maleic anhydride-co-chloromethyl styrene), $\mathrm{P}(\mathrm{MA}-\mathrm{co}$-CMS), poly(maleic anhydride-co-methyl methacrylate), P(MA-co-MMAc) and poly(maleic anhydride-co-methacrylate) $\mathrm{P}(\mathrm{MA}-\mathrm{co}-\mathrm{MAc})$, copolymers with indole in the presence of $\mathrm{NaH}$ at $-5^{\circ} \mathrm{C}$. Compositions of the copolymers were obtained using related ${ }^{1} \mathrm{H}$ NMR spectra and the polydispersity indices of the copolymers determined using gel permeation chromatography (GPC). The anhydride group possesses a higher reactivity with the indole group. The ring opening reaction between the anhydride group and the indole is simple and fast. All the resulted polymers were characterized by FT-IR and ${ }^{1} \mathrm{H}$ NMR spectroscopic techniques. The glass transition temperature $\left(\mathrm{T}_{\mathrm{g}}\right)$ of all the copolymers was determined by dynamic mechanical thermal analysis (DMTA). All the polymers containing indole groups showed a high glass transition temperature in comparison with the unmodified copolymers (I-IV). It was found that these polymers with indole moieties have high thermal stability and the presence of bulky indole groups in polymer side chains leads to an increase in the rigidity of polymers.
\end{abstract}

\section{G R A P H I C A L A B S T RACT}

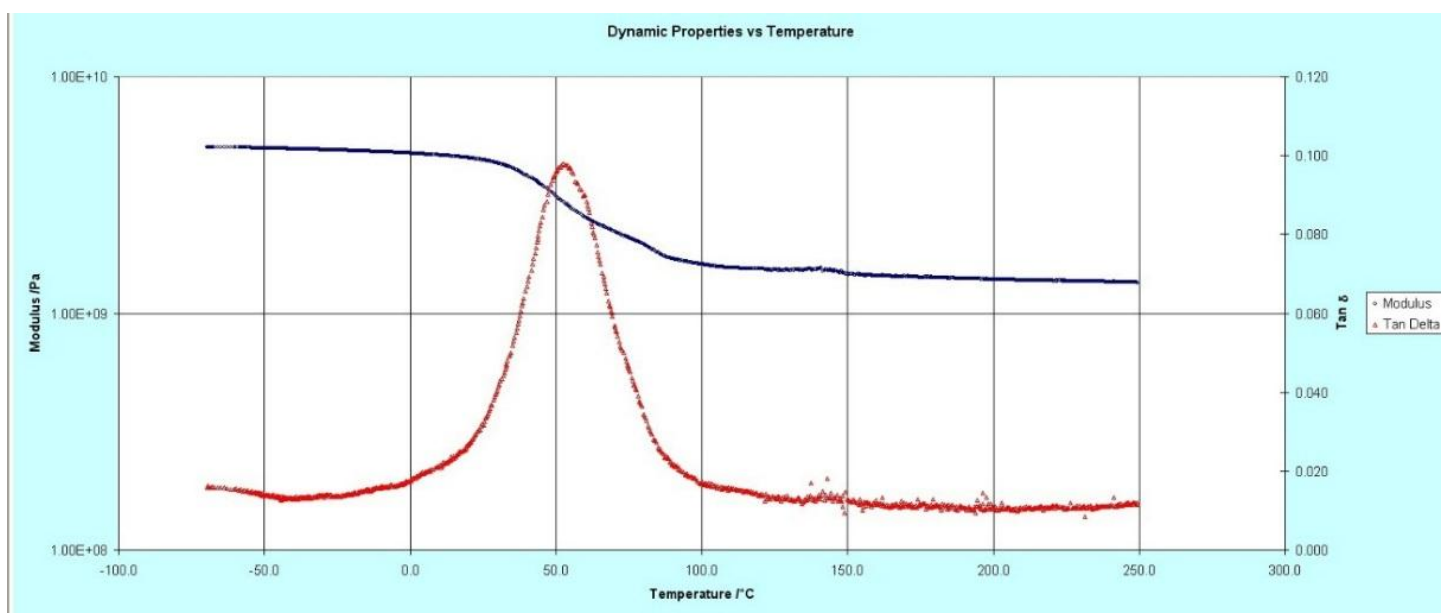

\footnotetext{
* Corresponding author's E-mail address: Nasirtabrizi@gmail.com, tabrizi952016@gmail.com, Tel.: +984517722763

Department of Applied Chemistry, Islamic Azad University, Ardabil Branch, Ardabil, Iran.
} 


\section{Introduction}

The interest for maleic anhydride (MA) copolymers is continuously growing, due to their successful application in various industrial processes or in medicine and pharmacy [1]. Maleic anhydride has an extremely low tendency, to homopolymerize in a radical polymerization and copolymerizes with a variety of donor monomers [2]. Copolymers of maleic anhydride are commercially available; bearing reactive anhydride groups, these anhydride groups present in the polymer chain can easily undergo an opening reaction with nucleophilic reagents which contain hydroxyl or amine groups [3-5]. Anhydride moieties in polymers are chemically reactive toward oxidized surfaces and form strong bonds of the carboxylate type [6]. The presence of anhydride moieties results in low backbone flexibility and consequently a high $\mathrm{T}_{\mathrm{g}}$ [7] .

Chemical modification of polymer structures is an important route for modification of polymer properties such as mechanical, thermal and surface properties [8-12]. The glass transition temperature is an important intrinsic characteristic that influences the properties of a polymer and its potential applications. Furthermore, polymers with high glass transition temperatures are attractive for polymer industrial science because of strong economic rewards that may arise from their potential applications [13].

Indole derivatives have been a topic of substantial research interest and continue to be one of the most active areas of heterocyclic chemistry, particularly due to their natural occurrence and pharmacological activities. In recent years, considerable attention has been paid on the synthetic methods leading to indole derivatives. Various indole derivatives, such as 3 substituted indole [14] and indolocarbazole [15] are common components of drugs. Indole derivatives also occur widely in many natural products such as those from plants, fungi and marine organisms [16].

From our knowledge, there is no information about the incorporation of indole group to maleic anhydride polymer. Thus, this present research work describes the incorporation of indole group to maleic anhydride polymers. Study of thermal properties of the obtained polymers by DMTA curves showed that the supporting of bulky indole groups as side chains leads to stiffness of the polymer chains and an increase in glass transition temperature.

\section{Experimental}

All reactions were carried out under nitrogen atmosphere to exclude oxygen moisture form the reaction systems. 


\section{Materials}

Solvents such as chloroform, DMF and diethyl ether and chemical material such as indole, CMS MA, MMA, St were obtained from Merck and distilled under reduced pressure to remove inhibitors before use. The radical initiator of azobis (isobutyronitrile) (AIBN) was purchased from Merck and purified by recrystallization from absolute ethanol. Sodium hydride (60\%) obtained from Aldrich chemical company.

\section{Measurements}

The infrared spectra were recorded on Bruker spectrometer scientific 500 IR in $\mathrm{KBr}$ discs. ${ }^{1} \mathrm{H}$ NMR spectra were run on a Bruker $300 \mathrm{MHz}$ spectrometer at room temperature using chloroform- $\mathrm{d}$ and dimethyl sulfoxide- $\mathrm{d}_{6}$ as solvent and TMS as internal standard. Dynamic mechanical thermal analyses (DMTA) were characterized by Triton (Tritec 2000 DMN) with heating rate of $5{ }^{\circ} \mathrm{C} / \mathrm{min}$ in air.

\section{Copolymerization of maleic anhydride} with (MAc), (MMAc), (CMS) and (St)

\section{General procedure}

Poly (MA-co-MAc) (I), poly (MA-co-MMAc) (II), poly (MA-Co-CMS) (III) or poly (MA-coSt) (IV) were synthesized as follows. In a Pyrex polymerization tube, mixture of $1.96 \mathrm{~g}$ (20 mmol) of MA, $0.065 \mathrm{~g}(0.4 \mathrm{mmol})$ of AIBN and $1.72 \mathrm{~g}$ ( $20 \mathrm{mmol})$ of MAc, or $0.5 \mathrm{~g}$
(20 mmol) of MMA or $2.08 \mathrm{~g}(20 \mathrm{mmol})$ of St

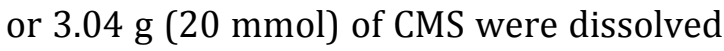
in $15 \mathrm{ml}$ related solvent. Polymers I and II were dissolved in ethyl acetate, that of III and IV were dissolved in toluene and acetone respectively. Then the ampoules were degassed, sealed under vacuum and maintained at $70 \pm 1{ }^{\circ} \mathrm{C}$ in a water bath and shaken by a shaker machine for about $24 \mathrm{~h}$. The viscous solutions were poured from the ampoules into $150 \mathrm{~mL}$ of cooled methanol (I), ethanol (II), toluene (III) and petroleum ether (IV) separately. The precipitates were collected and washed with the mentioned solvents for several times and dried under vacuum at room temperature. The yields of copolymers are presented in Table 1.

For I: ${ }^{1} \mathrm{H}$ NMR (DMSO-d 6 , $250 \mathrm{MH}_{\mathrm{z}}$ ) ppm: 1.6$2.7\left(3 \mathrm{H},-\mathrm{CH}_{2}-\mathrm{CH}\right), 3.9(2 \mathrm{H},-\mathrm{CH}-\mathrm{CH}), 3.55$ $\left(3 \mathrm{H},-\mathrm{OCH}_{3}\right)$; FT-IR $\left(\mathrm{KBr}, \mathrm{cm}^{-1}\right): 3005,2957$ (aliphatic C-H), 1733 ( $\mathrm{C}=\mathrm{O}$ ester), 1849, 1781 ( $\mathrm{C}=0$ stretching of anhydride unit), 1223, 1169 (C-0 ester), 1101, 1059 (C-O-C) For II: ${ }^{1} \mathrm{H}$ NMR (DMSO- $\mathrm{d}_{6}, 250 \mathrm{MH}_{\mathrm{z}}$ ) ppm: 0.76-1.20 (3H, $\left.-\mathrm{CH}_{3}-\mathrm{C}\right), 1089-2.47(2 \mathrm{H},-$ $\left.\mathrm{CH}_{2}-\mathrm{C}-\right), 3.53\left(3 \mathrm{H},-\mathrm{OCH}_{3}-\mathrm{C}\right), 4.07(2 \mathrm{H},-\mathrm{CH}-$ CH-); FT-IR (KBr, cm-1): 1857, 1785 (C=0 stretching of anhydride unit), 1730 (C-0 ester), 2999, 2956 (aliphatic C-H), 1240, 1150 (C-0 ester).

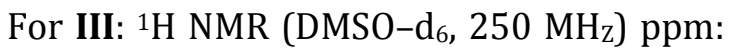
4-4.5 $\left(\mathrm{CH}_{2} \mathrm{Cl}\right)$, 7-7.5 (Ar-H of styrene), 3.5 $(2 \mathrm{H},-\mathrm{CH}-\mathrm{CH}) ; \mathrm{FT}-\mathrm{IR}\left(\mathrm{KBr}, \mathrm{cm}^{-1}\right): 1880,1770$ 
( $\mathrm{C}=0$ stretching of anhydride unit), 3060, 2887 (aliphatic $\mathrm{CH}), 1220\left(\mathrm{CH}_{2} \mathrm{Cl}\right)$.

For IV: ${ }^{1} \mathrm{H}$ NMR (DMSO-d 6 , $250 \mathrm{MHz}_{\mathrm{z}}$ ppm: 70.1 (Ar-H of styrene), $4.32(2 \mathrm{H},-\mathrm{CH}-\mathrm{CH})$, 1.6-2.8 (2H, $\left.-\mathrm{CH}_{2}-\mathrm{C}-\right)$; FT-IR ( $\left.\mathrm{KBr}, \mathrm{cm}^{-1}\right)$ : 1860, 1780 ( $\mathrm{C}=0$ stretching of anhydride unit), 1602, ( $\mathrm{C}=\mathrm{C}$ aromatic 3002 (C-H of aliphatic).

\section{Attachment of indole group to the side chain of copolymer (I-IV)}

Poly (MA-co-MAc), poly (MA-co-MMAc), poly (MA-co-CMS) and poly (MA-Co-St) containing indole groups were prepared as follows. In a $100 \mathrm{~mL}$ two-necked flask equipped with a dropping funnel, argon atmosphere and magnetic stirring, sodium hydride ( $4 \mathrm{mmol}, 0.96 \mathrm{~g}$ ) was slowly added to indole ( $5 \mathrm{mmol}, 0.58 \mathrm{~g}$ ) dissolved in $15 \mathrm{~mL}$ of DMF at room temperature for $30 \mathrm{~min}$. After this time, the mixture were cooled to $5{ }^{\circ} \mathrm{C}$ in ice-salt mixture while vigorous stirring. Then solution of polymers (I-IV) (2.5 mmol) in $15 \mathrm{~mL}$ of DMF was added drop wise within $1 \mathrm{~h}$. The contents were kept at ambient temperature for another $3 \mathrm{~h}$ while stirring the mixture of (I, II, IV) where then poured drop wise into a large excess of cold water then $5 \mathrm{~mL} \mathrm{HCl} \mathrm{37 \%} \mathrm{added} \mathrm{drop} \mathrm{wise}$ within the contents and keep in $0^{\circ} \mathrm{C}$ for $15 \mathrm{~h}$. But the mixture of III $15 \mathrm{~mL} \mathrm{HCl} \mathrm{37 \%} \mathrm{added}$ drop wise within the contents and keep in 0
${ }^{\circ} \mathrm{C}$ for $80 \mathrm{~h}$. The precipitated solid was recovered by filtration washed successively with water. The resulted polymers were dissolved in $50 \mathrm{~mL}$ diethyl ether for removing surplus indole. Finally the polymers containing indole substituents in the side chains were collected and dried under vacuum at room temperature.

For $\mathbf{I}_{\text {In: }}{ }^{1} \mathrm{H}$ NMR (DMSO-d 6 , $250 \mathrm{MH}_{\mathrm{z}}$ ) ppm: 2.27-1.85 (2H, $\left.-\mathrm{CH}_{2}-\mathrm{CH}\right), 6.3-7.9(\mathrm{Ar}-\mathrm{H}$ of indole), $11.04(1 \mathrm{H}, \mathrm{O}-\mathrm{H})$; FT-IR $\left(\mathrm{KBr}, \mathrm{cm}^{-1}\right)$ : 3060 (Ar-H of indole), 2400-3400 (OH acid), 1637 ( $\mathrm{C}=0$ amide), 1770 ( $\mathrm{C}=0$ acid).

For $\mathbf{I I}_{\text {In }}{ }^{1} \mathrm{H}$ NMR (DMSO-d ${ }_{6}, 250 \mathrm{MH}_{\mathrm{Z}}$ ) ppm: 0.92-1.78 (3H, $\left.-\mathrm{CH}_{3}-\mathrm{C}-\right)$, 2.48-2.85 (2H, $\mathrm{CH}_{2}-\mathrm{CH}$ ), 6.3-8.6 (Ar-H of indole), 11.08 $(1 \mathrm{H},-\mathrm{OH})$; FT-IR $\left(\mathrm{KBr}, \mathrm{cm}^{-1}\right): 3393$ (Ar-H of indole), 1651 ( $\mathrm{C}=0$ amid), 1734 ( $\mathrm{C}=0$ acid), 2400-3400 (-OH acid).

For III In: ${ }^{1} \mathrm{H}$ NMR (DMSO-d $6250 \mathrm{MH}_{\mathrm{Z}}$ ) ppm: 2.49-2.85 (2H, in $\left.-\mathrm{CH}_{2}-\mathrm{CH}\right), 608-7.9(\mathrm{Ar}-\mathrm{H}$ of indole and styrene), $10.85(1 \mathrm{H}, \mathrm{O}-\mathrm{H})$; FTIR ( $\mathrm{KBr}, \mathrm{cm}^{-1}$ ): 3445 (Ar-H of indole and styrene), 1620 ( $\mathrm{C}=0 \mathrm{amid}), 2400-3400(-\mathrm{OH}$ acid).

For $\mathbf{I V}_{\text {In: }}{ }^{1} \mathrm{H}$ NMR (DMSO-d $6250 \mathrm{MH}_{\mathrm{z}}$ ) ppm: 2.41-2.85 (2H, $\left.-\mathrm{CH}_{2}-\mathrm{CH}\right)$, 6.3-7.9 (Ar- $\mathrm{H}$ of indole and styrene), 11.07 (1H, O-H); FT-IR $\left(\mathrm{KBr}, \mathrm{cm}^{-1}\right)$ : $3399(\mathrm{Ar}-\mathrm{H}$ of indole and styrene), 1720 ( $\mathrm{C}=0$ acid), 1638 ( $\mathrm{C}=0$ amide), 2400-3400 (1H, $-\mathrm{OH})$. 


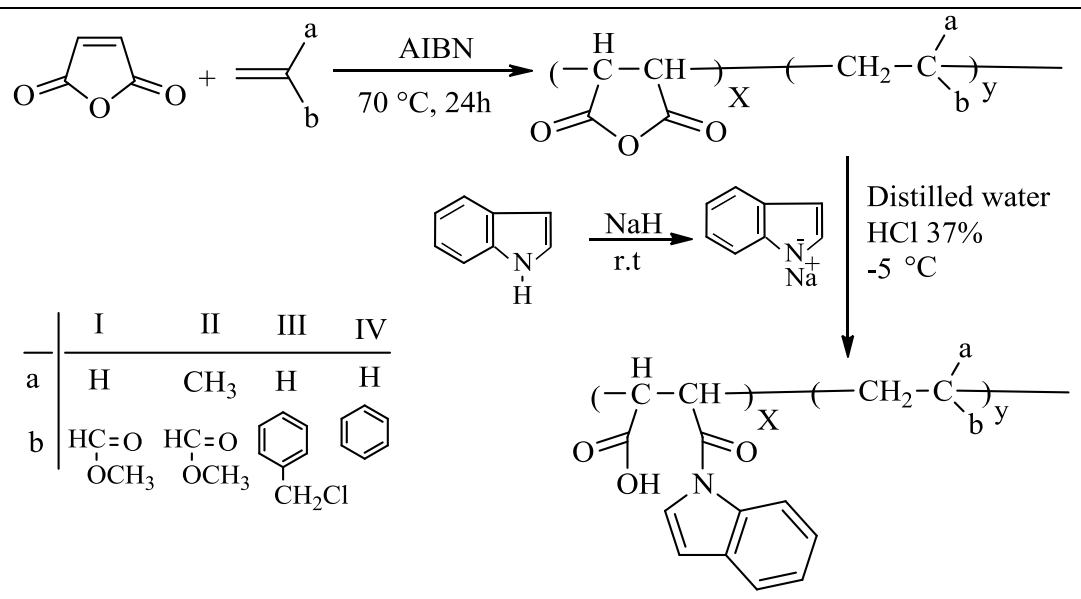

Scheme 1. (a) Copolymerization MA with (MAc, MMAc, CMS and St) monomers; (b) Synthesis of sodium indole salt; (c) Reaction of MA copolymer with indole salt

Table 1. The conditions of preparation of polymers (I-IV) at $70{ }^{\circ} \mathrm{C}$

\begin{tabular}{cccccccc}
\hline Sample & $\begin{array}{c}\text { Manomer } \\
\mathbf{1}\end{array}$ & $\begin{array}{c}\text { Manomer } \\
\mathbf{2}\end{array}$ & $\begin{array}{c}\text { Amount of 1 } \\
\text { in mmol }\end{array}$ & $\begin{array}{c}\text { Amount of 2 } \\
\text { in mmol }\end{array}$ & $\begin{array}{c}\text { Time } \\
\text { (h) }\end{array}$ & Weight & Yield\% \\
\hline I & MA & MAc & 20 & 20 & 24 & 3.3 & $\% 89$ \\
II & MA & MMAc & 20 & 20 & 24 & 2.9 & $\% 73$ \\
III & MA & CMS & 20 & 20 & 24 & 3.2 & $\% 64$ \\
IV & MA & St & 20 & 20 & 24 & 4.2 & $\% 74$ \\
\hline
\end{tabular}

Macromolecular grafting is a synthetic approach that involves the functionalization of a reformed polymer backbone containing reactive groups with an appropriate reagent. Since polymer properties are often heavily influenced by the identity of their pendant groups, a variety of different materials with a wide range of properties can be synthesized from only one antecedent. The use of maleic anhydride copolymers is attractive because of the variability in their properties achieved through the introduction of different comonomers. Furthermore, these copolymers contain the reactive anhydride unit, which offers possibilities for subsequent chemical modification of the polymer in order to tune the electrical and optical properties. Maleic anhydride copolymers can be modified by lowmolecular-weight compounds containing active hydrogen (water, alcohols or amines) because of the reactivity of the anhydride functions. In the recent study, functionalization of maleic anhydride copolymers by grafting indole were achieved in the presence $\mathrm{NaH}$ at $-5^{\circ} \mathrm{C}$.

The maleic anhydride (MA) monomer was copolymerized with methacrylate (MAc), methyl methacrylate (MMAc) in ethyl acetate, chloromethyl styrene (CMS) in toluene and styrene (St) in acetone at 
$70 \pm 1^{\circ} \mathrm{C}$ using $\mathrm{AIBN}$ as the radical polymerization initiator to obtain $\mathrm{P}(\mathrm{MA}-\mathrm{CO}-$ MAc) (I), P(MA-co-MMAc) (II), P(MA-coCMS) (III) and P(MA-co-St) (IV) copolymers respectively (Scheme 1). The reaction conditions are shown in Table 1 . The resulted copolymers are color solid and soluble in chloroform, $\mathrm{N}, \mathrm{N}$-dimethyl form amide and dimethyl sulphoxide.

Indole was reacted with the copolymers I-IV in the presence of sodium hydride at $-5^{\circ} \mathrm{C}$ to yield $\mathbf{I}_{\mathbf{I n}}-\mathbf{I} \mathbf{V}_{\text {In }}$ with an isolation yield of 65$85 \%$. The ring-opening reaction resulted in the formation of carboxyl and amide groups (Scheme 1).

The principal evidence for construction of functional groups onto polymers is appearance and loss of IR and ${ }^{1} \mathrm{H}$ NMR peaks that correspond to the introduction or transformation of distinct functional groups in each stage. The obtained ${ }^{1} \mathrm{H}$ NMR spectra for the modified copolymers (I-IV) show that indole is in corporate with some of the anhydride groups. It also shows that within the corporation of anhydride groups by indole group the peak around 6-7 ppm corresponding to two methylene protons of anhydride in MA disappeared and new acidic proton peaks appeared around 10-11 ppm owing to ring opening reaction of anhydride group (Figure 1). The infrared spectra of the modified products show the broad characteristic of $(\mathrm{O}-\mathrm{H})$ group at wave number of $2600-3000 \mathrm{~cm}^{-1}$ and new peak appeared $1630 \mathrm{~cm}^{-1}$ corresponding to carbonyl of the amide group and corresponding to two carbonyl groups of the MA copolymers revealed that the other group remained during the reaction (Figure 2).

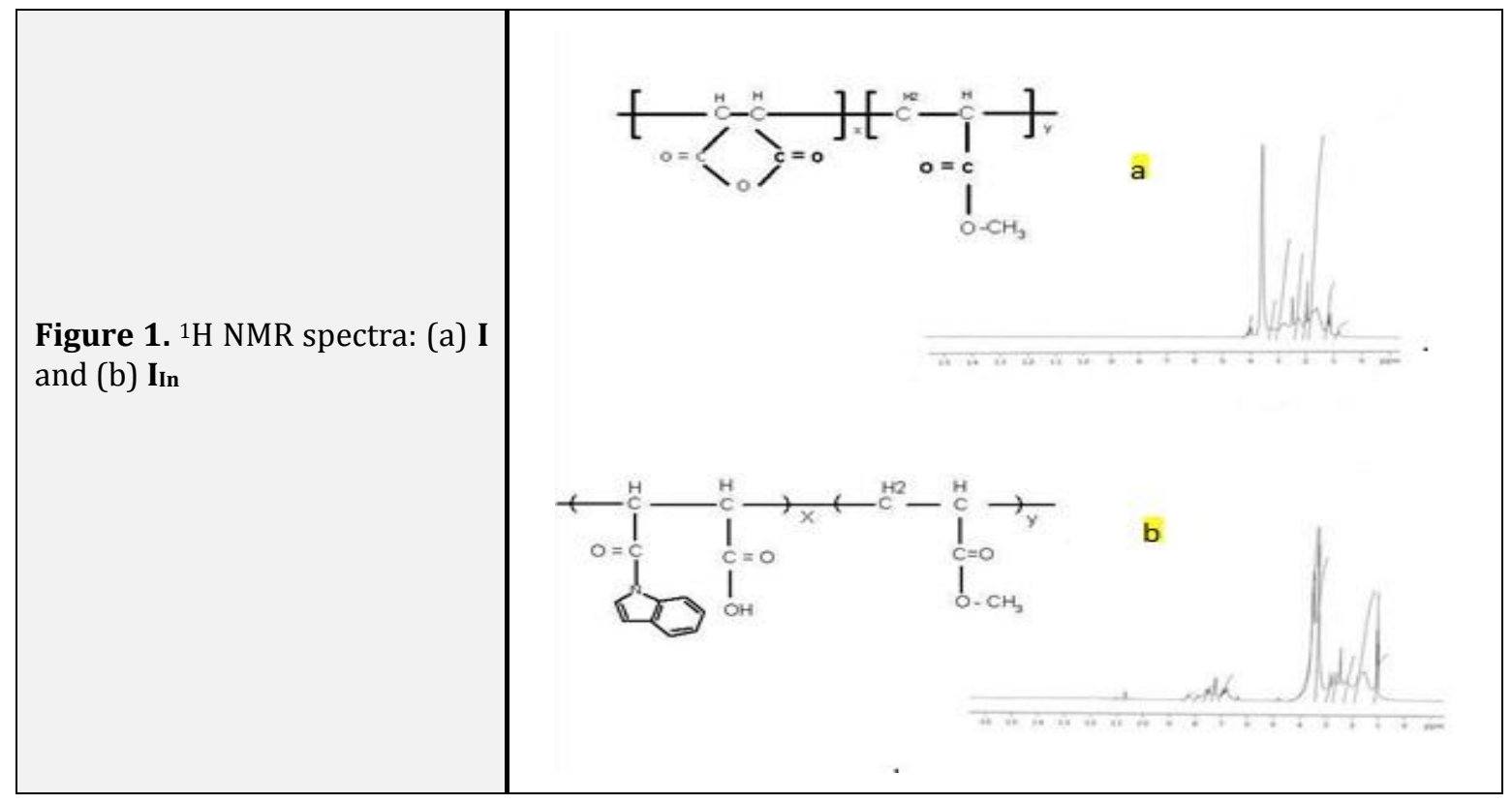


Figure 2. Infrared spectra of (a) II and (b) IIIn



NMR analysis data were calculated according to the following equations:

$$
\frac{A m 1(\mathrm{CH})}{\text { Atotal }}=\frac{n 1 m 1}{a 1 m 1+b 2 m 2}
$$

$\frac{A m 2(\text { OCH } 3 \text { or OCH2 })}{\text { Atotal }}=\frac{n 2 m 2}{a 1 m 1+b 2 m 2}$

$m 1+m 2=1$

Where $A m_{1}$ and $A m_{2}$ are the normalized areas per $\mathrm{H}$ from the corresponding functional groups of the monomer unit regions in ${ }^{1} \mathrm{H}$ NMR spectra; $A_{\text {total }}$ is the total area of protons in the copolymer; $\mathrm{n}_{1}$ and $\mathrm{n}_{2}$ are the integers of proton(s) in the functional group of the monomers $a$ and $b$ are integers of protons in the monomer units $\left(\mathrm{m}_{1}\right.$ and $\left.\mathrm{m}_{2}\right)$, monomer unit ratios can be calculated from Eqs. (1) and (2) using the following simplified from:

$\frac{m 1}{m 2}=f=\frac{n 2 A m 1(C H)}{n 1 A m 2(\text { OCH } 3 \text { or OCH } 2)}$ 
Table 2. Molecular weight and $\mathrm{T}_{\mathrm{g}}$ of MA copolymers

\begin{tabular}{ccccc}
\hline Polymer & $\mathbf{M w} / \mathbf{1 0}^{\mathbf{3}}$ & $\mathbf{M n}_{\mathbf{n}} / \mathbf{1 0}^{\mathbf{3}}$ & $\mathbf{M w} / \mathbf{M}_{\mathbf{N}}$ & $\mathbf{T}_{\mathbf{g}} \mathbf{~}^{\circ} \mathbf{C} \mathbf{)}$ \\
\hline I & 37.4 & 19.35 & 1.94 & 56 \\
II & 39.2 & 19.8 & 1.97 & 85 \\
III & 28 & 15.5 & 1.8 & 139 \\
IV & 32.1 & 16.05 & 2.0 & 55 \\
\hline
\end{tabular}
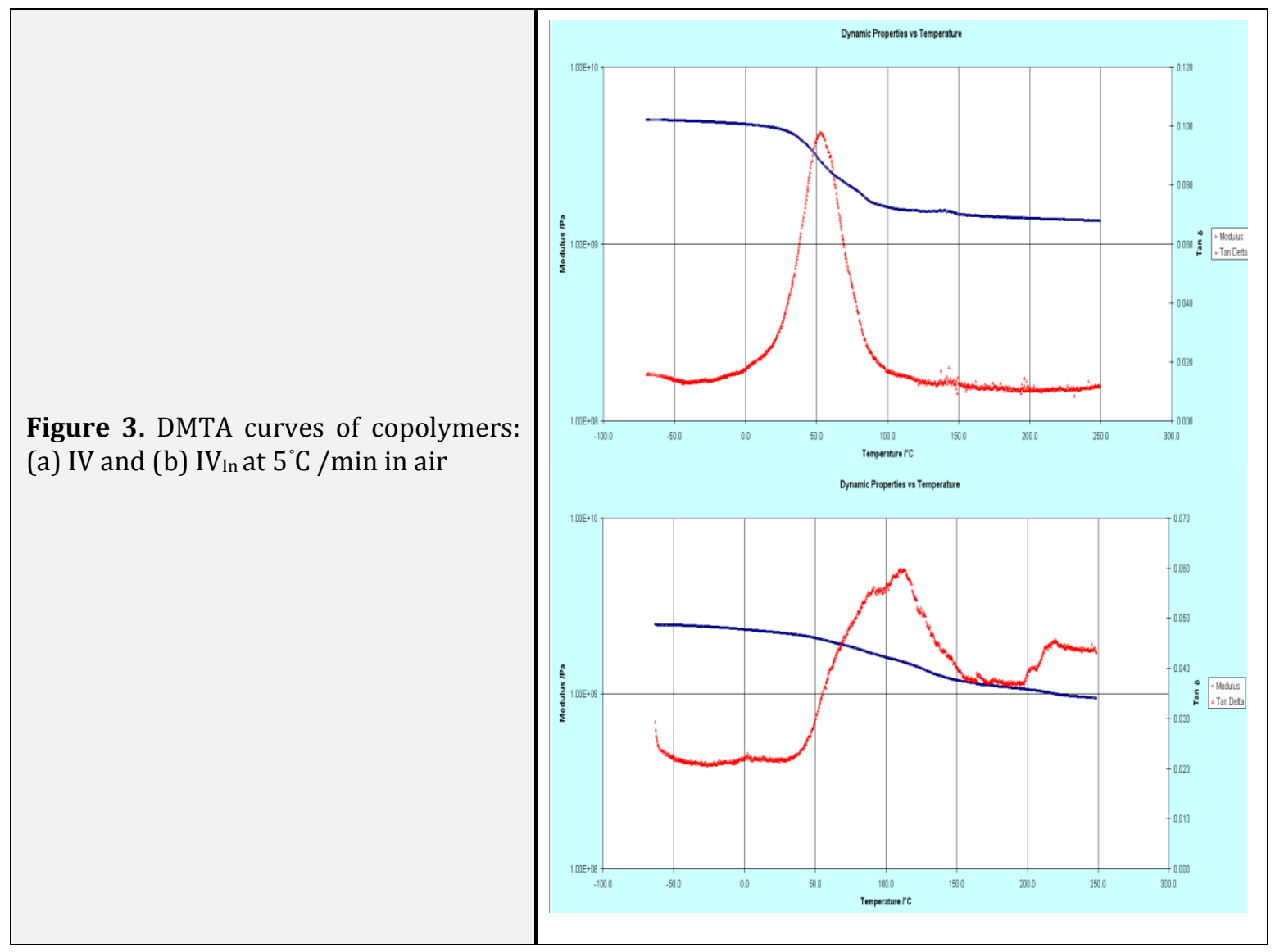

Table 3. The molar composition of copolymer (I-IV) with indole

\begin{tabular}{cccccc}
\hline Polymer & MA (mol \%) & MAC (mol \%) & MMA (mol \%) & CMS (mol \%) & St (mol \%) \\
\hline I & 55 & 45 & - & - & - \\
II & 53.5 & - & 46.5 & - & - \\
III & 45 & - & - & 55 & - \\
IV & 52 & - & - & - & 48 \\
\hline
\end{tabular}

Table 4. The result of reaction between $2 \mathrm{mmol}$ of each polymer (I-IV) with indole

\begin{tabular}{cccc}
\hline Modified Copolymer & Weight (g) & Yeild (\%) & T $_{\mathbf{g}}$ ( $\left.^{\circ} \mathbf{C}\right)$ \\
\hline $\mathrm{I}_{\text {In }}$ & 0.35 & 70 & 111 \\
$\mathrm{II}_{\text {In }}$ & 0.36 & 72 & 80 \\
$\mathrm{III}_{\text {In }}$ & 0.28 & 56 & 182 \\
$\mathrm{IV}_{\text {In }}$ & 0.35 & 10 & 127 \\
\hline
\end{tabular}




\section{Conclusions}

The copolymers of MA with MMAc, MAc, CMS, and St (I-IV) were synthesized by free radical solution polymerization and the copolymer compositions calculated by corresponding ${ }^{1} \mathrm{H} \quad$ NMR analysis. The resulted copolymers are soluble in chloroform, THF, N, N- dimethyl form amide and dimethyl sulpoxide and insoluble in diethyl ether and water. Characterization of all the obtained polymers were performed with FT-IR, and ${ }^{1} \mathrm{H}$ NMR spectroscopic techniques. The study of DMTA curves for the modified copolymers indicated that glass transition temperature values of the copolymer increase with incorporation of indole groups as side chains. The presence of the indole groups in polymer structures increases the rigidity of macromolecules and creates the modified polymers with novel properties and applications.

\section{Acknowledgement}

The authors thank the Islamic Azad University, Ardebil branch for technical supports during this research.

\section{Reference}

[1]. G.C. Chitanu, I. Popescu, A. Carpov, Rev. Roum. chim., 2006, 51, 923-929.

[2]. R.P. Nieuwhof, A.T.M. Marcelis, E.J.R. Sudholter, Macromolecules, 1999, 32, 13981406.
[3]. S.S. Hou, P.L. Kuo, Polymer. 2001, 42, 2387-2394.

[4]. L.P. Zhu, Z. Yi, F. Liu, X.Z. Wei, B.K. Zhu, Y.Y. Xu, Eur. polym. J., 2008, 44, 1907-1914.

[5]. M.H. Nasirtabrizi, S.J. Mousavi, Adv. J. Chem. A, 2018, 1, 56-65.

[6]. A.M. Al-Sabagh, M.N. El-Din, R.E. Morsi, M.Z. Elsabee, J. Petrol. Sci. Eng., 2009, 65, 139-146.

[7]. M. Bruch, D. Mader, F. Bauers, T. Loontjens, R. Mulhaupt, J. Polym. Sci. Pol. Chem., 2000, 38, 1222-1231.

[8]. A. Kowalewska, W.A. Stanczyk, S. Boileau, L. Leytel, J.D. Smith, Polymer, 1999, 40, 813-818.

[9]. K.D. Safa, H.A. Eram, M.H. Nasirtabrizi, Iran, polym, J., 2006, 15, 249-257.

[10]. Y.H. Kim, S.K. Kwon, S.K. Choi, Macromolecules, 1997, 30, 6677-6679.

[11]. K.D. Safa, M.H. Nasirtabrizi, Eur. Polym. J., 2005, 41, 2310-2319.

[12]. X.F. Niu, Y.L. Wang, Y.F. Luo, J. Pan, J.F. Shang, L.X. Guo, Chinese Chem. Lett., 2005, 16, 1035-1038.

[13]. S.W. Kuo, H.C. Kao, F.C. Chang, Polymer, 2003, 44, 6873-6882.

[14]. X. Mi, S.J. Luo, J. Cheng He, Tetrahedron Lett. 2004, 45, 4567-4570.

[15]. M.J. Slater, S. Cockerill, R. Baxter, R.W. Bonser, K. Gohil, C. Gowrie, J. Edward Robinson, E. Littler, N. parry, R. Randall. W. Snowden, Bioorgan. Med. chem., 1999, 7, 1067-1074. 
[16]. A.K. Bhatt, P.K. Shah, H.G. Karadia, H.D. ～[18]. U.S. Kumar, R. Balaji, A. Prasath, S.

Patel, Orient. J. Chem., 2003, 19, 643-647.

Nanjundan, J. Macromol. Sci. A., 2001, 38, 67-

[17]. R.R. Jayakumar, S. Balaji, Nanjundan, 78.

Eur. Polym. J., 2000, 36, 1659-1666.

How to cite this manuscript: Mohamad Hosein Nasirtabrizi*, Hamideh Saberi Khosroshahi, Synthesis and Characterization of New Polymer Systems Containing Indole, Adv. J. Chem. A, 2019, 2(3), 256-265. 